\title{
PETER GALBÁCS*
}

\section{LUCASIAN MICROFOUNDATIONS AS A FORM OF STRUCTURAL REALISM**}

\begin{abstract}
This paper is an attempt to understand Robert E. Lucas's microfounded models of the 1960-70s as results of a structuralist project. It is argued that the way Lucas derived macroeconomic outcomes from the decisions of market agents is in line with the basic tenet of the semirealist version of structural realism, where structures are conceived as relations emerging between properties of relata under specific conditions. Accordingly, after an overview of semirealism, it is emphasized that in his microfoundations project Lucas formulated the basic decision problem so that large-scale fluctuations could plausibly be traced back to agents' properties. The transition from Lucas and Rapping's model of the labor market to Lucas's monetary island model is described as placing the same decision makers in a setting the specifics of which are in consonance with the assumed actions and interactions of market participants.
\end{abstract}

Keywords: Robert E. Lucas, business cycle theory, microfoundations, entity realism, structural realism, semirealism

* Budapest Business School, 1055 Budapest, Markó u. 29-31, Hungary, e-mail: Galbacs.Peter@uni-bge.hu, ORCID: oooo-0003-0381-5486.

** The paper was supported by the János Bolyai Research Scholarship of the Hungarian Academy of Sciences. Some parts of this story were presented at the January 28, 2019, session of the Philosophy, Politics and Economics workshop run by the Center for the Study of Economic Liberty, Arizona State University. Helpful comments were received from the attendees, especially Ross B. Emmett, Scott Scheall, and Edward C. Prescott. My warmest appreciation goes to Łukasz Hardt and one of my anonymous referees for their suggestions reaching far beyond the responsibilities of editors and reviewers. 


\section{INTRODUCTION}

Building theories on explicit microfoundations has become one of the hallmarks of modern macroeconomics. According to its basic tenet, societies consist of individual agents, phenomena emerging at the social level must thus be conceived as being in accordance with or directly stemming from the behavior of individual agents. ${ }^{1}$ The microfoundations program subscribes to a two-layer notion of societies, where there is a micro-level inhabited by economic agents (such as firms, households, and employees) who act in a somehow defined institutional setting and whose actions and interactions lead to some supra-agent or macro-level outcomes. The emphasis between the levels may change (Hoover 2012), while the core idea in every variant is to explain supra-individual phenomena in terms of individual decisions.

The setting in which agents make their decisions plays a crucial role in the emergence of supra-individual outcomes. As parts of the environment surrounding decision-makers, the microeconomic universe contains some genuinely macroeconomic entities, such as some aggregates like GDP or the general price level and its changes (Hoover 2009). Accordingly, Robert E. Lucas incorporated such "additional" elements into his models of large-scale fluctuations of the 1960-70s. Lucas's (1972) agents are tied to the macro: subject to the signal extraction problem, they confuse local and aggregate price dynamics, they use money issued by the central government, their rational expectations are identified with the outputs from an overall macro-model, and the budget constraint for the representative agent is the national income in per capita terms. Likewise, Lucas (1980: 710-711) also admits that agents cannot act and interact in a vacuum - the institutional environment with its rules and constraints defines what agents can and cannot do or know. Or as Lucas puts the same idea:

I think the basic view of economics that Hume and Smith and Ricardo introduced, taking people as basically alike, pursuing simple goals in a pretty direct way, given their preferences, where you are trying to explain differences in behavior by differences in the situation people are finding themselves in rather than differences in their culture, their inner wiring, inner workings, their race, whatever, their class, just thinking about people as people and then trying to account for their behavior in terms of how they are responding to their environment, that this is it for economics. (Lucas 2004: 21-22)

${ }^{1}$ The microfoundations project is a manifestation of methodological individualism (social phenomena are to be explained in terms of individual decisions), which as a belief is underpinned by the "trivially true" (Blaug 1992: 44-45) idea of ontological individualism (only individuals are existent, so collective phenomena stem from individuals' actions). 
Microfounded macroeconomics is thus supposed to pay close attention to the way the environment affects action and interaction of agents having specific characteristics. This idea of looking at societies as conglomerates made up of agents acting in various settings bears close resemblance to structural realist philosophies of physics, where, loosely put, structures are conceived as complex wholes consisting of interrelated parts called objects (Chakravartty 2007: 119).

These philosophies come in various forms and maintain diverse views on the way parts constitute structures, but they have one thing in common: what we know of the structure is supposed to be related somehow to what we know of the parts. Different schools of thought on the matter differ in what they think we have knowledge of. In cases where the objecthood of relata is dubious (i.e., relata cannot unambiguously be regarded as objects), like in quantum mechanics and in its metaphysics (ontic structural realism), the ontological weight is placed on structures. The result is a thin notion of objects that have no intrinsic natures but relational properties only. As compared to the case of intrinsic properties that objects have irrespective of the outside world, relational properties are delivered by relations (Ellis 1991). In this latter case, everything we know about relata, conceived as mere nodes of relations, comes from the structure. Although the identification of quantum objects in the usual metaphysical sense is problematic (Castellani 1993, French 1998: 94-107), its applicability in the social sciences cannot be taken for granted (Cao 2006: 41-42) as, to say the least, it may easily lead to a complete elimination of individuals. If one thinks of human societies as formed by individuals having intrinsic properties, one would reject such an extreme structuralist interpretation. However, Ross (2008) and Kincaid (2008) argue that modern economics, by depriving the homo oeconomicus of its fundamental human character and simplifying the individual into its positions in structures, has subscribed to such a purely structuralist reconceptualization of man and society after all. Here the knowledge of men as relata allegedly stems from the knowledge of the embedding structure.

Semirealism (Chakravartty 1998, 2007) reverses this direction and derives structural knowledge from the knowledge of relata. Semirealism as a philosophy emphasizes that these two forms of knowledge, the knowledge of objects and the knowledge of their relations, are inseparable and, as such, imply each other. If we have knowledge about the properties of objects, it also informs us about the way objects act in relations - and, vice versa, the knowledge of structure implies the knowledge of the intrinsic properties of objects. Here the ontological weight is on objects and their intrinsic properties. They are conceived as the primary existents, and relations are of deriva- 
tive character only (Chakravartty 2012: 190). The properties of the related objects and the properties of their structure form a close-knit unity in which the behavior of the supra-object level (a structure) stems from the properties and the implied behavior of its parts. ${ }^{2}$

In what follows, it is argued that the way Lucas placed his macroeconomics on choice-theoretical foundations in the 1960-70s reveals a structuralist interest of this kind. Using the usual target-vehicle distinction from the theory of surrogative reasoning (Swoyer 1991, Galbács 2020: 284-328), Lucas regarded societies as structures made up of individual decision makers (structure as target) and represented them with model economies built as structures of representative agents and other objects (structure as vehicle). Accordingly, he endowed his agents with specific properties and dropped them into specific settings that established the ways agents interacted, so macro-level outcomes as the working of the structure stemmed from individual actions. The theory of the optimizing behavior of the individual market participant, be it a firm, an agent, or a household, constitutes the microfoundations from which the behavior of complex systems like industries or national economies is conceived to result. This dependence between the micro-level of market participants and the macro-level, as it is claimed, is the same as the dependence semirealism describes in the case of physics.

\footnotetext{
${ }^{2}$ It is a tempting option here to call into play the huge literature on weak and strong forms of emergence. The problem of emergence regards the relationship between the set of properties of wholes (called systems, structures, etc.) and the set of properties of parts (called interrelated objects or entities, relata, etc.). In weak emergence, the properties of a system follow from the properties and hence the actions and interactions of its parts. By contrast, under strong emergence a system has properties arising independently of the properties of parts (Bedau 1997). In the social sciences, just like in physics (e.g., hydrodynamics), we have models where system behavior seems to be irreducible to the level of interrelated parts (Garfinkel 1981). This paper, however, addresses a different contrast, since the structuralist philosophies surveyed here do not call into question the intimate connection between the properties of wholes and parts. Rather, our question is pointed at what Lucas thought about the primacy of the properties of wholes and parts - whether it is the structure whose properties determine the properties of relata (as ontic structural realism assumes) or vice versa (as semirealism assumes). Systems may admittedly have natures that are unexplainable in terms of the properties of constituent parts (Chakravartty 2007: 160-162), but the question whether Lucas derived the relevant system behavior patterns from agents' properties (and not the other way round) can be answered without going into whether societies have properties irreducible to properties of individuals and other microlevel entities. So, in this paper, expressions like "the emergence of a structure" or "a structure emerges" by no means imply a subscription to either weak or strong emergence; they only mean that a structure exists, irrespective of whether its properties stem from the properties of relata or not.
} 
By highlighting the twofold dependence of the macro-level on market participants' intrinsic properties and the environment in which they are supposed to act, this paper contributes to the discussion initiated by Hoover (2001, 2008, 2009) and Epstein (2009, 2014). To discredit Lucas's models, they argued that intrinsic properties of market participants on their own are insufficient to carry the macro-level, therefore they regarded Lucas's idea of explaining large-scale fluctuations in terms of individual decisions as untenable. By contrast, here it is shown that Lucas conceived decisions as taking place in specific settings, so he rendered the macro dependent on decisions as well as on how the environment affects behavior. Consequently, in his microfounded models, the decision makers are not the only but still the dominant causal entities in societies (Manicas 2006: 75, 92). It follows that Lucasian microfoundations cannot be undermined by pointing out that models must contain elements other than market participants - this is exactly what Lucas took into account when setting up his models.

Section 1 thus provides a brief overview of semirealism to aid a better understanding of the role that objects' intrinsic properties play in establishing structures. At first, the emphasis will be placed on the case of unobservable entities, only to introduce in general an intimate connection between objects' properties and relations later. Section 2 turns to Lucas and his rationale for building economics on proper microfoundations. The reconstruction of Lucas's stance is underpinned by extensive quotes from the Lucas archives, so the paper is an addition to the growing body of literature devoted to his unpublished materials. This section is intended to underline that Lucas applied structure in a twofold sense: society is a structure of market participants that must be represented by structures of representative agents. His arguments are interpreted in terms of the semirealistic view of the dependence between structure and entity properties to point out that Lucas set up his choicetheoretic framework to capture the elementary decisions underlying some relevant macroeconomic phenomena. As it would be an untenable anachronism, it is of course not argued that Lucas was a "semirealist." It is certainly argued, however, that semirealism is an effective (but certainly not the only) philosophy to explain what kind of properties ought to be assumed at the micro-level to yield a meaningful macroeconomic theory, and why the behavioral influences of the environment must be considered.

As a case study, section 3 gives an in-depth look into the transition from Lucas and Rapping's (1969a, b) models of the market for labor force to Lucas's (1972) first fully fledged monetary island model. The section offers a detailed analysis of how Lucas and Rapping defined the core decision problem and placed it in an incomplete information setting. It is argued that the Marshallian 
framework they applied was irreconcilable with the information problem, so agents in the model could not have behaved in the presumed way. Lucas solved this inconsistency between behavior and environment by placing the same agents in a different setting. Such a change in the environment has an effect on how agents behave and what macro-level conclusions can consistently be drawn from the model - which as a tenet is in line with the semirealistic view that objects' properties are no more than dispositions for behavior, and conditions play a key role in the realization of behavior and hence relations.

\section{HOW SEMIREALISM UNDERSTANDS THE STRUCTURES AS EMANATING FROM OBJECT PROPERTIES}

Semirealism has risen as a synthesis of some opposing philosophies of physics. Entity realism stands on the one end of the scale. According to its main adherent, Ian Hacking (1982), one can be certain about the existence of some unobservable objects without being certain about the truth of theories that describe how such objects behave and hence stand in relations. He sets manipulability as the basis of existence claims. If we can systematically employ an object in experimental settings to understand the effects of its application on other entities (Chakravartty 2017a: 18), there is no ground for doubting the existence of the object. Hacking's main point is to base existence claims on the causal properties of objects (if we can trigger some effects with an object, the object must be existent), while withholding belief in the truth of theories that describe how objects work or behave and stand in relations. This is meant to be a case for separating knowledge of objects from knowledge of their structure - which as a stance is hard to defend (Elsamahi 1994), as Hacking derives existence claims from what an object can do to other objects exposed to it. What we know about an object stems from how the object behaves in relations, and hence in structures. ${ }^{3}$

It is the various forms of structural realism that occupy the other end of the scale. At bottom, structural realism, which is skeptical about the existence of unobservable objects, forms another attempt to detach knowledge of objects

${ }^{3}$ In the structuralist philosophies surveyed here structures are referred to as systems of relations. This definition also sheds some light on why it is straightforward to understand societies as systems of market relations, and hence as structures. This understanding of societies (i.e., structure as target) is taken for granted here. 
and their intrinsic properties from knowledge of structures.4 This skepticism, however, takes different forms. In the moderate version, epistemic structural realism (ESR), the existence of unobservable objects remains mainly unquestioned - they do exist or may probably exist, to say the least (French, Ladyman 2011: 27). Even though unobservables are hidden behind an impassable epistemic obstacle (Chakravartty 2003: 867-868), their properties are unknown to us, and even their existence may be uncertain, it is still possible for us to have true descriptions of structures and the causal relations in mathematical terms (Psillos 1995: 23, Morganti 2004: 81). And if it is possible to know how objects are related, there is no need for further knowledge of them. Knowledge of structures is thus not supposed to imply knowledge of the related parts, including what they are and how they behave (Ladyman 1998: 413).

Ontic structural realism (OSR) is the extreme version. Here philosophers form definite claims on the existence of unobservable objects, which are regarded as non-existents and as such eliminated from the ontological furniture of fundamental physics. 5 Just like ESR, ontic structuralists also believe that describing reality in structural terms is possible without having knowledge about the nature of unobservables, but as a further step OSR breaks with the commonly assumed dependence between relations and relata (Morganti 2004: 102). In order to emerge, a structure no longer needs related objects, so structures are not simply privileged over objects, but ontologically autonomous (Ladyman 1998: 420, van Fraassen 2007). As a result, OSR purports to offer complete knowledge of the world (French 2010: 91, Esfeld 2013): if it is only structures that exist, then structural realists have complete knowledge of the world.

For many, this inference is ungrounded as it seems unjustified to extend the consequences of an epistemological obstacle (that stands in the way of the observation of unobservables) into an ontological statement (what you cannot see cannot exist). In a milder, non-eliminative version of OSR, some allowance is thus made for the existence of unobservable objects as relata, but they are still deprived of the possibility of having intrinsic properties. If an object endowed with no serious metaphysical commitment has no intrin-

\footnotetext{
4 Historically, structural realisms were intended to be an effective answer to some arguments against scientific realism, especially the pessimistic meta-induction (Worrall 1989). Even if theories may turn out to be wrong in terms of the postulated natures of objects, this fact by no means undermines the truth of theories in a structuralist sense. Similar points were made in favor of entity realism: theoretical descriptions of entities may change, sometimes they become falsified, but the existence of objects they are about cannot be questioned (Hardin, Rosenberg 1982).

5 Here OSR is labelled as an extreme version of ESR only in that OSR has replaced ESR's agnosticism and uncertainty about the existence of unobservables with a flat denial.
} 
sic but only extrinsic or relational properties, everything we know of it follows from what we know of the structure.

So far, we have discussed some conflicting views regarding structures. Entity realism holds that the properties of objects imply no reliable theory of how objects are related: Objects reveal themselves while their structures remain hidden. By contrast, in one way or another both ESR and OSR hold that structural knowledge fails to inform us about the intrinsic properties of relata: Structures reveal themselves while objects remain hidden or are simply inexistent. To get over the shortcomings of either of these positions, semirealism combines the knowledge of relata with the knowledge of structures. It is thus a form of structural realism, but involves no skepticism about the natures of objects: Structures are conceived as stemming from the intrinsic properties of relata.

Semirealism was motivated by the idea that, in their basic forms, both entity realism and the ESR-OSR variants of structural realism are untenable and incompatible. The main rationale for semirealism is the two-way implication between being realist about objects and being realist about structures. As Hacking has argued, belief in the existence of a certain class of objects is supposed to be fed by experiences about their causal roles. However, this knowledge yields more than a simple belief in existence (Resnik 1994): the result is inevitably a theory that describes the relations such objects have and the causal mechanisms they are involved in. We always perceive entities, be they observables or unobservables, via the way they behave in interactions: what they do to each other, to entities of other types, or to our senses (Esfeld 2009). Such experiences, however, inform us about the properties of objects that underlie their actions and interactions. It is thus the properties of objects that establish their behavior in relations - causal roles and causal regularities that Hacking emphasizes stem from causal properties. Accordingly, the existence claims one forms about objects in an entity-realist fashion imply massive knowledge about the relations, and hence about the structures objects constitute. Entity realism cannot tenably be separated from structural realism.

Conversely, structural knowledge involves knowledge of entities. Any description of any structure inevitably speaks volumes about the nature of the relata as well (Stanford 2003: 570). ESR and OSR believe that the natures of objects are somehow beyond their structures: structure is knowable, while objects are transcendent or even inexistent. However, the case against entity realism has already shown that there can be no meaningful break between the intrinsic properties of objects and the structure they form. When we talk about the nature of an entity, then we talk about the way it behaves in relations, and vice versa: when we talk about a structure of objects, then we talk 
about the way objects behave in relations, and thus about their intrinsic properties (Psillos 1995). No structure can be understood without knowledge about the behavior entities show in relations (Morrison 1990). Intrinsic properties underlying a structure (or, in other words, causally, hence structurally active intrinsic properties) reveal themselves simultaneously with structural knowledge, structural knowledge is thus the same as knowledge of intrinsic properties (Psillos 2001: S17). Structural realism cannot tenably be separated from entity realism - structural knowledge presupposes and involves firm knowledge about objects.

Entity realism and structural realism thus imply each other and collapse into semirealism. Here a structure is understood as a system of relations between the first-order or intrinsic properties the relata have - it is therefore true that structures consist of related objects, though relata are structured only indirectly, through their properties. The way objects are related is directed by the way their intrinsic properties are related (Chakravartty 2007: 89-90). Relations emerge in cases where the underlying properties are present and the objects possessing the necessary characteristics are under such conditions that the relations can come into existence. In short, relations, hence structures, are dependent upon the conditions under which objects show up - while it is still untrue that properties come from the structure as structural realists hold (Chakravartty 2012: 196, Galbács 2020: 218-219). The intrinsic properties of objects are thus only dispositions for certain relations but do not automatically bring in relations (Chakravartty 2004: 157). It is the problem of manifestation. Even if the necessary qualities are given, a relation emerges only if the necessary conditions are also given. Even if a bar of redhot iron can cause an ice cube to melt, this will happen only if the ice cube is exposed to the iron bar - changes in temperature require a specific relation between the objects. They are supposed to be close enough, to say the least, and it is their own, intrinsic properties that make such changes possible (and not the other way round - it is not because of melting the ice cube that the bar of iron is red-hot). Likewise, even if an agent wants to sell a product that another agent is willing to buy, the transaction cannot occur if they do not show up on the same market - if their relation is not facilitated by their meeting. To address an associated problem, in section 3 we will see how a change in conditions influences the information sets agents can plausibly possess and what consequences it leads to at the macro-level.

Before proceeding, let us summarize the previous discussion. The controversy to which semirealism offers an effective answer concerns the ontological status of unobservable objects, their properties, and the role they play in the emergence of structures. As we have seen, the semirealist view understands 
the way objects are related as stemming from the intrinsic properties of objects. Via the causal role an entity plays in relations, we certainly have some experience of it, so there is no need to abandon our commitment to its existence and its properties. At one point in the discussion, however, we moved to the simpler case of observables like economic agents. There is no doubt as to their existence, even if OSR does not regard "obviously" existing objects as good models for the fundamental level of quantum objects (Ross 2008). Accordingly, semirealism is not used here as a point in favor of the existence of economic agents (which would be an uninteresting slam-dunk case) but to emphasize the intimate connection pointing from the properties of parts towards the working of their structure. Given this intimacy, an abstract or partial representation of a structure and the implied causal mechanisms requires one to endow the objects with such properties that carry the real counterpart of the causal mechanism one intends to highlight (Galbács 2020: 221-223). Accordingly, Lucas's microfounded monetary macroeconomics will be described below as a representation of social structures where supra-agent outcomes, the macroeconomic consequences of individual decisions, follow from the assumed verisimilar properties of agents and the details of the settings in which the agents act and interact. Sections 2 and 3 thus interpret Lucas through a semirealist lens, as he had no doubts regarding the existence and characteristics of economic objects (so ESR does not hold), and because, to his mind, the structure was not the origin of the natures of relata (so OSR does not hold).

\section{HOW LUCAS EXPLAINS THE NEED FOR MICROFOUNDATIONS}

In Lucas's theorizing practice, microfoundations come into play in all cases where a supra-agent level, the behavior of an industry or a complete national economy, is derived from the basic choice-theoretic framework pitched at the microeconomic level. Lucas started applying this approach at the very beginning of his career. In his dissertation (Lucas 1964) and its abridged version he published a few years later (Lucas 1969), he started out with assumptions about a single firm, parts of which were a production function and the assumption that the optimizing firm responds to changes in product and factor prices by adjusting its production and input utilization. He then proceeded to the industry level by assuming that all firms in the industry operate under the same presumptions and are faced with the same prices. He thus constructed an industry out of a set of identical firms, so he could estimate the firm-based model on market-level data. 
However, this "microfoundational" interest was not exclusive during these early years. Lucas $(1965 / 1981,1967 a)$ elaborated a version of the firm optimization problem where he supposed the firm to be optimizing on the capital input under the assumption that capital costs are dependent on the speed of investment - the quicker the firm wants to close up the gap between its current capital stock and its desired level, the higher adjustment costs it faces. Here Lucas solely focused on the firm optimization problem, with no interest in a supra-firm level. Neglecting the implications between the levels was only temporary, though. Lucas (1967b) soon returned to this firm optimization problem, where the speed of capital adjustment is penalized with extra costs, and after solving the firm problem to yield investment and labor force plans in the face of changing prices, he derived a complete industry with supply and investment demand functions.

Simultaneously with the evolution of the firm problem, Lucas approached the labor supply decision as a utility-maximizing response of workers to changing prices and wages (Lucas, Rapping 1969a, b, 1972). The result was an aggregate-level labor supply function that could reconcile short-run nonneutrality with long-run neutrality of money as facts of life. A part of the problem was the assumed slowness in expectations formation, which Lucas and Rapping built on an information deficiency assumption. As a solution, it was different from the firm's static or certainty-based rational expectations Lucas applied in his firm models. We shall return to this information deficiency and expectations formation problem in section 3 as a key antecedent to Lucas's (1972) monetary model.

Lucas's career thus abounds in models shaped around his basic choice theory, aimed at understanding supra-agent problems in terms of individual decisions. Surprisingly, it is difficult to find published texts from our relevant period where Lucas explicitly made the case for microfoundations - texts where he explains in detail why it is important to trace industry-level or macroeconomic phenomena back to the basic decisions of agents, and what such microfoundations ought to look like. ${ }^{6}$

One of the few exceptions is his "Understanding Business Cycles," a summary paper from 1977, where Lucas closely followed his earlier arguments against Keynesian macroeconometrics of the time. In a series of papers from

\footnotetext{
${ }^{6}$ In the years Lucas launched his microfounded monetary macroeconomics, in a series of papers Debreu (1974), Sonnenschein $(1972,1973)$ and Mantel (1973) pointed out that microeconomics can carry the macro-level only under strict conditions. In the case of the artificial societies consisting of the replicas of the one and only representative agent that Lucas assumed this problem does not arise (Kirman 1992). As Hoover (2012: 51) argues, Lucas was probably unaware of Debreu, Sonnenschein, and Mantel's qualms.
} 
the second half of the 1970s, Lucas, partly accompanied by Thomas J. Sargent, explained why Keynesian models were unlikely to predict the effects of alternative policy scenarios despite their past empirical success. As Lucas (1973/1976) argued, one cannot expect future reliability as long as the forecasts neglect the behavioral effects of policy measures and regard the superficial behavioral parameters as invariant (Sargent 1977: 2-3, Lucas, Sargent 1979: 6). Policy interventions may break past behavioral rules - even if they are detected as stable for a long time. By contrast, Lucas (1977) suggested that economic analysis should dig down to the level of the genuinely stable economic primitives such as taste and technology to predict policy-induced outcomes on this solid basis. His conclusion was straightforward. To understand macroeconomic dynamics, we need to understand the basic decision problems that the agents solve and that are relevant to the emergence of large-scale fluctuations. This involves a threestep process: first, the core decision underlying large-scale fluctuations must be identified; second, agents in models must be assumed to face the same decision problem; and third, in surrogative reasoning, dynamics of model-worlds must be compared to facts to learn how the target works (Galbács 2020: 302). Lucas (1973/1976) thus iterates there and back again between structure as target (a society) and structure as vehicle (a microfounded model).

Again, his published texts of these years are of little help regarding the identification of the core decision problem - these papers cannot help us to go beyond some commonplaces like the idea that the microeconomic foundations of macroeconomics ought to be in line with the evidence we have on the basic tendencies of agents' decisions and on the circumstances agents consider (Lucas 1977: 16-17). Likewise, when considering the directions of post-war business cycle theory, Lucas (1980: 710-711) only reiterates the same idea: the central decision problem underlying models of business cycle is well-known from the abundant microeconomic studies and surveys. However, in some drafts from the same period, the mid-1970s, Lucas explains that the basic decision problem to serve as the microeconomic foundation for macroeconomics regards the labor supply decision of workers: 7

\footnotetext{
7 The Lucas papers, his unpublished notes, drafts, teaching materials and correspondence stored the David M. Rubenstein Rare Book \& Manuscript Library, Duke University, have a special relationship to his published works. It is a common pattern that Lucas preparing for a paper to be published took plentiful notes in which he clarified to himself the theoretical and methodological foundations underpinning his published works. In most cases, therefore, drafts shed light on such aspects of problems that the final versions take for granted and hence remain silent about. De Vroey's (2016) History was the first book to extensively quote from the Lucas papers. A few years later I surveyed a wider textual basis taken from the unpublished works (Galbács 2020). The present paper fits in this sequence by providing a look into further drafts and notes.
} 
What we do mean by an explanation of a unique event like the Depression is, I think, an account of how these summary figures could have been generated by a combination of individual decisions, decisions arrived at in a way that is consistent with other evidence we have about economic decision making, and perhaps unique external events or "shocks." We need, in other words, to try to see the Depression from the inside out, not to label the behavior the term "depression" summarizes but to be able to reproduce it as an intelligible response, chosen by people as intelligent and informed (but not more so) as we are, to the situations they found themselves in.

In any situation, economic actors are making a lot of interrelated decisions more or less simultaneously, but I suggest we begin by thinking of the decision that is most central to the event we are trying to understand: the decision as to how much to work (for pay, either in the form of wages and salary, or of income from self-employment).... We begin, then, with the question: How, in general, do people decide how much of their time to allocate to work-for-pay? (Typed notes. Lucas papers. Box 13. Folder "Barro, Robert, 1974, 2000, undated"; original emphasis)

After studying firm supply behavior and labor supply decisions as distinct albeit related puzzles, Lucas (1972) unified the problems by assuming away changes in the capital stock and technology. To keep things as simple as possible, by so doing Lucas could reduce changes in production to changes in individual labor supply. The resulting choice-theoretic model of macroeconomic fluctuations assumes that swings in macroeconomic performance result from agents' responses to changes in prices in an incomplete information environment, where the money supply due to its changes is regarded as the primary source of shocks. In the spirit of Friedman (1968) or Friedman and Schwartz (1963), Lucas was convinced that in reality nothing but money can be the causal instrument that is capable of influencing the decisions of market agents (Galbács 2020: 284-314). So, in sum, good macroeconomics for Lucas considered the role money played in macroeconomic fluctuations through affecting individual supply decisions.

Now we are one step closer to the core idea of the Lucasian microfoundations: money is the causal trigger that works through individual optimizing responses. However, we have so far learnt nothing about the requirements Lucas set against good microfounded models - how should real-world agents' responses to monetary changes be represented in microfounded models? How should the modeler ensure the resemblance between the decision of market participants and the decision of the representative agent? In short, what should the microfoundations look like? At greatest length, Lucas addressed this problem in his preliminary notes he took for "Adaptive Behavior and Economic Theory" (Lucas 1986). In the published paper, Lucas voices his basic creed that models of individual decisions including microfounded macroeconomics ought to pay attention to changes in the decision rules agents 
follow, since agents responding to changes in the environment revise their decision rules from time to time. In the drafts, however, he dwells on some key characteristics of good theories:

My view on the relationship between economic and psychological (or behavioral) theory is taken from H. A. Simon, as developed, for example, in The Sciences of the Artificial [Simon (1969/1996)]. There, Simon distinguishes between the "inner environment" of the agent under study, the way the agent "works," and his "outer" or "task environment." For some purposes we can usefully model an agent's behavior on the basis of a good description of his outer environment and only a very rudimentary sketch of his workings. For other purposes, the nature of the inner environment will need to be at the center of a useful model. Thus (to take one of the many concrete examples Simon's lectures use to make its points) under normal circumstances, a bridge is simply "a surface for conveying traffic," and a traffic engineer needs to know nothing else about the bridge than this description of its purpose, its "task environment." For other purposes, when the capacity of the bridge is at the center of the question, one needs to know much more: the structure of the bridge, the materials from which it is built, the stress characteristics of these materials - a description of its "inner environment." Deciding which features of the bridge need to be taken into account in modeling it is not a matter of deciding which are "true," but of deciding which can safely be abstracted from for the set of questions at hand. (Typed notes. Lucas papers. Box 27. Folder "Adaptive Behavior, 1985-1986"; original emphasis)

Lucas goes on to point out that to understand how a firm responds to changes in its environment, even if it is people who make the decisions, there is no need for us to know anything about "who these people are, how they are organized to interact, who in the group is responsible for which decisions." In Simon's phrasing, we do not need to know much about the firm's inner environment. When studying the basic decisions of economic agents, most of the components of the inner environment can thus be neglected as unimportant - just like in other disciplines of human behavior that disregard the aspects that economics emphasizes. In general, models must be relevant to the phenomena they address (Hardt 2018):

Human behavior is such a complex subject that one can hardly be surprised that different disciplines have arisen that study aspects of it from very different points of view. All of these disciplines progress by abstracting a very limited set of features that seem important for behavior and focusing on these to the exclusion of others. The coexistence of so many different "models of man," [in] H. A. Simon's phrase, gives an appearance of irreconcilable conflict: They can't all be true. But the conflict is largely superficial and easily resolved: none of these models is "true." The natural sciences have long worked with many mutually inconsistent "models of matter." Why should we be different?

Economics and psychology differ, in part, because they address themselves to different questions. (Hand-written notes. Lucas papers. Box 27. Folder "Adaptive Behavior, 1985-1986"; original emphasis) 
Here Lucas makes a case for powerful abstractions. ${ }^{8}$ It is the problem under study that drives the theorist's hand when it comes to deciding what to preserve and what to disregard. The result is a plurality of theories where alternative (and not necessarily competing) theories approach the same thing like individual decision makers from various directions. Any of these theories focuses on that aspect of the relevant entity (in our case of interest, man as a human being) that is essential in terms of the basic interest of the analysis:

From this point of view, it seems to me easy enough to see how it is that economists, psychologists, organization theorists and others may usefully study the same entities from very different points of view, just as traffic engineers and structural engineers can both work with different, useful models of a bridge. (Typed notes. Lucas papers. Box 27. Folder "Adaptive Behavior, 1985-1986")

The key message is thus selectivity. Business-cycle theorists need to find that aspect of man as an economic agent, that decision problem that is central to the occurrence of large-scale fluctuations. In semirealist parlance, this is a case for deriving supra-agent outcomes (macroeconomic dynamics) from a given set of structurally active intrinsic properties of agents (regarding the labor supply decision an economic agent is supposed to make). Lucas argued:

In economics, we have the mathematically impressive theory of general equilibrium, in which a set of axioms about individual behavior and the way in which individuals are assumed to interact imply a variety of propositions about the nature of the system as a whole. (Typed notes. Lucas papers. Box 27. Folder “Adaptive Behavior, 1985-1986”)

At an abstract level, for Lucas, microfounded macroeconomics thus worked with models that conceived economies as systems or structures formed by individual decision makers - both in reality and on the scratch pads of economists. The picture of the individual in these models were sketchy and superficial, which is in complete consonance with that principle of the theory of representation that only those properties of the target are to be preserved in representing vehicles that play a crucial role in the emergence of the phenomena under scrutiny (Contessa 2007, Suárez 2002, 2004). If one believes, as Lucas did in these years, that the most plausible causal mechanism behind business cycles is the informed decisions agents make in response to changes in the money supply, then he needs no more details than the core decision

\footnotetext{
${ }^{8}$ Abstraction in the sense Lucas applies here refers to a conceptual technique when only some facets of the objects or their processes to be represented are preserved in models, while all other facets are disregarded, omitted, or assumed away. Abstractions are true, even if their truth is partial. As a result, they lead to unrealistic (or in Lucas's phrasing, untrue) models in descriptive terms, so they cannot convey the whole truth (Mäki 1992, Chakravartty 2007: 187-192).
} 
problem, some rules of interactions, and some assumptions regarding the environment in which the agents are assumed to act.

\section{A CASE STUDY: SEMIREALISM IN ACTION. THE MOVE FROM THE MODEL OF THE MARKET FOR LABOR FORCE TO THE MONETARY ISLAND MODEL}

Along the lines previously laid down, in this last section I analyze how the rules of action and interaction, and the effects of the environment cohere in two of Lucas's key models of the 1960-70s. Lucas and Rapping (1969b) set up a model to study the labor supply decision of workers in an incomplete information setting, where expectations had a key role in decision making. Their purpose was to reconcile the short-run non-neutrality with the longrun neutrality of money in a model that explicitly takes into account the transition between the short-run and the long-run. To this end, they emphasized the role of expectations workers form about, on the one hand, nominal wages and, on the other, prices, hence real wages. These expectations may turn out to be incorrect, and, as Lucas and Rapping assumed, workers make different decisions depending on whether their expectations are correct or not. If expectations are incorrect, after a while they need to be revised, and it is this revision process that describes the transition from the short run to the long run. However, and this is the key message of the discussion below, a crucial consequence stemming from the assumptions underlying the expectation formation mechanism of agents was inconsistent with the setting, and in a later version of the model Lucas abandoned the basic Marshallian framework. The story of this change from Lucas and Rapping's (1969b) labor market model to Lucas's (1972) neo-Walrasian monetary island model can instructively be told in the language of that tenet of semirealism that the environment of objects exerts an influence on their actions and interactions (Ellis 2008, Chakravartty 2017b). As a by-product, this section also offers an insight into how Lucas put his ideas on proper theorizing, reviewed in section 2 above, into practice.

As a first step, Lucas and Rapping defined the basic decision problem in its simplest and most relevant form. They took it as evidently given that real wage exerts an influence on the labor supply through multiple channels like its effect on the size of the population through child-bearing decisions, on the participation rate, or the man-hours any agent decides to supply. These channels are facets of a complex decision agents are supposed to make, so the 
labor supply as an aggregate-level quantity is derived from the preferences taken as properties of agents, the fundamental objects of the structure. Lucas and Rapping simplified this complicated decision into a decision on hours supplied and participation rate, studied in a basic utility analysis of goodsleisure choice. ${ }^{9}$

On this basis they defined a representative household that was supposed to optimize on current goods consumption, current labor supply, future consumption, and future labor supply. Taking into account the fact that the present value of consumption cannot exceed the present value of all income (there was thus a common budget constraint), they arrived at the schedule of current aggregate labor supply as a function of current real wage, real wage expected for the current period (in short, expected real wage), prices expected for the current period, $P_{t}^{*}$ relative to current prices, $P_{t}$, (in short, price expectations error), and the stock of non-human assets. The part of the function containing the price expectations error takes the form

$$
+\beta_{3}\left[r_{t}-\ln \left(P_{t}^{*} / P_{t}\right)\right]
$$

which can easily be rearranged as

$$
\left.+\beta_{3} r_{t}-\beta_{3} \ln \left(P_{t}^{*} / P_{t}\right)\right]=-\beta_{3}\left[\ln \left(P_{t}^{*} / P_{t}\right)-r_{t}\right]
$$

where $r_{t}$ is the nominal interest rate applied in present value calculations underlying the budget constraint. It is clear from expression (2) that prices higher than expected (or unexpected inflation) exert a positive influence on the labor supply, since in this case $0<P_{t}^{*} / P_{t}<1$ and hence $\ln \left(P_{t}^{*} / P_{t}\right)<0$. Given the negative sign on $\beta_{3}$ in (2), an underestimation of prices leads agents to increase their labor supply.

According to the labor supply schedule, this effect keeps working even if current real wages remain intact. This infuses the mechanism with an effect bearing superficial resemblance to the money illusion, which Lucas and Rapping wanted to avoid. Money illusion, "a myopic concentration on money values" (Lucas, Rapping 1969b: 732), implies the assumption that workers are ignorant of current prices, so under this assumption they are supposed not to be aware of their current real wages. In the case of the single Marshallian market, Lucas and Rapping believed such an assumption would have been difficult to maintain as that would have rendered it inevitable to explain why workers cannot discriminate between nominal and real wages - why would

9 This is an application of what Lucas thought about the role of abstraction we surveyed in the previous section. To put it into a semirealistic parlance, Lucas and Rapping assumed away some facets of the decision problem agents solve in reality to narrow their focus down to the one aspect that they thought to be relevant to the problem they studied. 
they focus on money wages when the prices they pay are also known to them?10 So instead, they opted for Tobin's (1952: 581) explanation on why workers tend to increase labor supply under inflation even when real wages remain stable:

\begin{abstract}
Labor may have inelastic price expectations; a certain 'normal' price level . . . may be expected to prevail in the future, regardless of the level of current prices. With such expectations, it is clearly to the advantage of wage earners to have, with the same current real income, the highest possible money income. For the higher their money incomes the greater will be their money savings and, therefore, their expected command over future goods.
\end{abstract}

As a result, Lucas and Rapping had a theory in which nominal price changes boost the labor supply in the short run without resorting to the money illusion. In this sense, given the description of the decision problem, money via its inflationary effects is non-neutral, and a negatively sloped Phillips curve emerges.

To stop the trade-off between inflation and unemployment from extending to the long-run, some further agent-level assumptions were needed. Accordingly, Lucas and Rapping (1969b: 731) assumed a slowness of revisions of wage and price expectations of agents. With instantaneous revisions, there would have been no trade-off and the short-run non-neutrality of money should have been abandoned - while with no revisions the trade-off would inevitably have covered the long-run, and the thesis of long-run neutrality could no longer have been maintained. To strike a balance between these extreme cases having implications opposing the facts (Lucas 1994), Lucas and Rapping presumed a simple adaptive mechanism with built-in tendencies pointing towards trend values. Until the gap between perceived and expected prices and wages is closed by the revision of expectations, agents feel an incentive to work more.

At this point, the theory needed further underpinnings. Lucas and Rapping (1969b: 735-739) explained agents' reluctance to modify their price and wage expectations on the spot with a reference to the role repeated experiences play in gradually convincing agents to overwrite their anticipations. Lucas and Rapping told their theory of expectations in a simple story about jobseekers judging job offers by comparing their expected or normal wages to current or available wages. Any unemployed person, as the story claims, faces a complex decision problem. Based on a comparison, the worker accepts a job if the offered wage is not lower that the wage the jobseeker regards as normal,

${ }^{10}$ Assuming money illusion, combined with further unexplained presumptions (Galbács 2015: 153-167), in the form Lucas and Rapping rejected, was a part of Friedman's (1968) Phillips curve. 
considering his qualifications, his and others' labor market experiences and other personal characteristics like age or sex. In the opposite case, the agent must decide whether to keep searching in the hope of better wage offers, or to lower his expected wage. In the first option, the agent believes that he received the previous job offer he has just declined out of bad luck, he thus maintains his normal wage rate and hence prolongs the search process (and remains unemployed on purpose). In the second option, however, he admits that his wage claim might have been excessive, so in the end he is willing to accept a job at a lower wage level. It is only after some rounds of rejection that the agent admits his expectations being too high, so any change in expectations takes time eventually - expectations thus change only slowly. The mechanism also works the other way round: when a jobseeker receives a wage offer higher than expected, he is supposed to discriminate between the effect of personal good luck and a general increase in wages. In the first option, he boosts his labor supply, while in the second no real adjustment is needed, only the expected wage rate needs to be bid higher.

The point of the story is agents' uncertainty over normal wages. ${ }^{11}$ In Lucas and Rapping's incomplete information setting no worker is assumed to be certain of either his normal wage or the time when it ought to be lowered or raised. It is this uncertainty that is supposed to lead market participants to gain recurring labor market experiences in job search to make decisions. Under certainty, by contrast, no agent would hesitate between real adjustment (reducing or increasing his labor supply) and changing his normal wage the necessary adjustment would be instantaneous. Lucas and Rapping thus attribute the transition from the short-run to the long-run and the fadingaway of the trade-off between inflation and unemployment to uncertainty and information deficiencies. By so doing, they called agent-level assumptions into play. What we can see at the aggregate level, the emergence of the long-run neutrality of money, is understood as the outcome of decisions the market participants make - just like in semirealism (Chakravartty 1998) where causal connections at the level of a structure (here, the neutrality and non-neutrality of money) are supposed to stem from the properties, actions, and interactions of the related objects (here, the details of the decision problem placed on expectations).

However, the story told this way was inconsistent. Lucas and Rapping assumed the labor market to be a single Marshallian market, where any uncer-

\footnotetext{
${ }^{11}$ Lucas and Rapping (1969b: 736) regarded this story about the search process and normal wages as a casual observation anyone can gain on everyday labor markets. This is a further illustration of how Lucas argued for the plausibility of the role individual decisions play in large-scale fluctuations.
} 
tainty over prices and wages could not plausibly be maintained. Although Stigler $(1961,1962)$ offered a way out by assuming that the idea of a single market by no means presupposes the rule of one price and the homogeneity of product, Lucas and Rapping insisted on one wage over the labor market (Martin Bronfenbrenner's letter to Lucas. November 30, 1970. Lucas papers. Box 1A. Folder "1 of 2, 1970"). With no Walrasian submarkets, however, any changes in wages must be general or global, which must be known to agents - there is thus no place for confusion. So, the case where an agent in Lucas and Rapping's framework thinks he experiences some favorable or unfavorable individual wage offer is simply inconsistent with the idea of the single Marshallian market. However, with every bit of information on wage and price dynamics freely available to agents, the transition between the short run and the long run would fall through. With no uncertainty given in a consistently single-market Marshallian story, the revision of expectations ought to be instantaneous, so there ought to be no gap between current and expected wages and prices - and Tobin's incentive to increase the labor supply ought to cease to work (let alone the money illusion). To get rid of this inconsistency, Lucas (1972), provoked by Phelps's (1970: 6-9) criticism, retold the same story in a neo-Walrasian setting, where agents act on isolated island markets, they are thus tenably deprived of knowledge about global price dynamics. Here utility-maximizing market participants face the same problem of deciding on the labor supply by telling apart, to put it in the language of the signal extraction problem, general or nominal and individual or real shocks to prices. The theory became consistent.

An aspect of the transition from Lucas and Rapping's Marshallian model to Lucas's Walrasian island framework was thus the fact that the setting in which agents are supposed to act has a crucial influence on behavior, action, and interaction - because properties are only dispositions for behavior, relations, actions, and interactions cannot be modelled without explicit appeal to the environment (Chakravartty 2007: 119-150). Accordingly, the same agents might behave in diverse ways in diverse settings - or, in other words, to force the same agents to behave in the same way in diverse settings might result in theoretical inconsistencies. By revisiting the problem of the macroeconomic effects of the same supply decision, Lucas elaborated a theory in which such inconsistencies between what agents are supposed not to know and what they plausibly cannot know do not arise (Lucas 1981: 7). At the same time, there is no historical evidence that Lucas was aware of the problem with the information deficiency assumption in his and Rapping's models and that he put forward the island model with a view to solving that. 


\section{CONCLUSIONS}

This paper has been an attempt to approach, from a semirealistic point of view, some aspects of the microfoundations program that Lucas carried out in his models of the 1960-70s. As it was argued, Lucas conceived societies as complex systems consisting of agents so that changes in the systems followed from corresponding changes in behavior of the constituent parts. For Lucas, simply put, macroeconomic dynamics is the outcome of individual decisions, where the decision maker is an atomistic market participant or a household, so the only way of understanding what we perceive at the macro-level is to understand what agents do. To Lucas, money was so powerful an instrument that it was the only candidate for a trigger that could plausibly lead to largescale fluctuations - he thus built his monetary business cycle theory on the compelling idea that money was the only thing capable of exerting a bias on the millions of decision makers towards the same direction. If most agents make the same decision, this fact has clearly detectable macroeconomic consequences, so macroeconomic outcomes root in the decisions of market participants (Galbács 2020: 322-328). If a huge part of market agents acts under the same general behavioral tendency, so if, plainly put, they tend to behave in the same way, this behavior will have visible consequences at the level of the society. Accordingly, if a lot of agents decide to work less, these individual decisions will add up, and the same effect will be observable in the society: worked hours will decline and hence the rate of unemployment will rise. To simplify the case, if every agent can be supposed to act in the same way (and they can, given the mass phenomenon of unemployment), the behavior of the society can adequately be modelled with the decision the one typical theoretical agent makes. This is a direct connection between macroeconomic outcomes and microeconomic properties. What the agent does reappears at the macro-level.

So, if microeconomics is the science of optimizing on scarce resources like financial assets or time, and if individual decisions have implications above the individual level, microeconomics is the basis from which macroeconomic phenomena stem - even if the microeconomic universe contains some inherently macroeconomic entities like money or some aggregates like the GDP or changes in the overall price level. As Manicas (2006) claims, agents must be the fundamental units in the social sciences - thus, the microfoundations program still makes sense, even if the individual on its own is an insufficient basis to carry the macro-level. Real-world market participants act and interact by making decisions in specific institutional settings, get in touch with 
specific instruments and other entities, some of which belong to the aggregate level or to the central government. Lucas's microfounded macroeconomics was thus no more than an endeavor to represent agents and macroeconomics as they are.

As it was argued, this basic creed of the microfoundations program is in line with the philosophy of semirealism, where changes to properties of a whole called "structure" were understood as corollaries of changes taking place at the level of constituent parts. To emphasize the plausibility of the semirealist philosophy, it was introduced as a synthesis between entity realism and some diverse forms of structural realism - all these philosophies infeasibly separate structural knowledge from the knowledge of entity properties. Semirealism, by contrast, understands any concrete structure as a set of relations between the properties of objects, so entity properties and structures form a close-knit unity. If the necessary conditions are given so that entities can encounter and engage in specific interactions, the behavior they are expected to show in interactions is dependent upon their properties.

This understanding of relations was used in the paper to underpin the analysis of how Lucas (1972) relocated Lucas and Rapping's (1969b) households from a Marshallian framework into a neo-Walrasian island model setting. In both cases, decision makers were supposed to be optimizing on their labor supply in the framework of the labor-leisure choice. In the decision they consider their nominal wages and the price level, hence real wages, so that expectations regarding the price level play a key role in agents' responses to changes in prices and wages. To discriminate between the short run and the long run, Lucas and Rapping assumed decision makers to be slow to revise their expectations. Here they resorted to a story, taken as an informal theory, according to which agents are confused over their real wages as they cannot tell apart global and local (personal) changes. This latter aspect of the story, however, was inconsistent with the assumed properties of agents and the setting in which they were supposed to act. The single Marshallian market provides decision makers with every bit of information, so on the solitary aggregate market agents cannot tenably be deprived of the knowledge necessary to correct judgments of real wages. Lucas (1972) could finally derive largescale fluctuations from information deficiencies in a plausible way when he retold the same story in a Walrasian system of isolated submarkets, where the notion of agents suffering from the same confusion, given their assumed characteristics, was in line with the setting.

This aspect of Lucas's microfoundations leads to my final point. When it comes to giving an account of causation, semirealism emphasizes the intrinsic properties of objects again. If properties lead an object to behave in cer- 
tain ways in interactions with other objects, so if it is these properties that determine what objects can do to each other and hence how they change each other, the resulting structures become causal structures. On this showing, building microfoundations for macroeconomics was a tenable strategy for understanding the behavior of social structures consisting of individual decision makers. However, to be in line with the circumstance that decision makers cannot carry the macro-level on their own, an explanation set up in terms of agent-level properties must take into account the way the environment influences behavior. Accordingly, when Lucas (1972) reformulated his and Rapping's theory of the labor market, he just refined the theory of information-based business cycles to be a genuinely causal account of large-scale fluctuations. As long as agents could not plausibly be assumed to behave in the way their characteristics determine, there must be something in the model to blame. In Lucas's case, this faulty part was the single Marshallian market: after replacing it, the story of business cycles stemming from the information deficiency that agents face became a plausible causal account.

\section{BIBLIOGRAPHY}

Bedau M. A. (1997), "Weak Emergence" [in:] Philosophical Perspectives: Mind, Causation, and World, J. E. Tomberlin (ed.), Malden: Wiley-Blackwell, 375-399. https://doi.org/ 10.1111/o029-4624.31.s11.17

Blaug M. (1992), The Methodology of Economics or How Economists Explain (2nd ed.), Cambridge: Cambridge University Press. https://doi.org/10.1017/CBO9780511528224

Cao T. Y. (2006), "Structural Realism and Quantum Gravity" [in:] The Structural Foundations of Quantum Gravity, D. Rickles, S. French, J. Saatsi (eds.), Oxford: Clarendon Press, 40-52. https://doi.org/10.1093/acprof:oso/9780199269693.003.0002

Castellani E. (1993), “Quantum Mechanics, Objects and Objectivity” [in:] The Foundations of Quantum Mechanics: Historical Analysis and Open Questions, C. Garola, A. Rossi (eds.), Dordrecht: Kluwer, 105-114. https://doi.org/10.1007/978-94-011-0029-8_9

Chakravartty A. (1998), "Semirealism," Studies in History and Philosophy of Science Part A 29(3), 391-408. https://doi.org/10.1016/soo39-3681(98)00013-2

Chakravartty A. (2003), "The Structuralist Conception of Objects," Philosophy of Science 70(5), 867-878. https://doi.org/10.1086/377373

Chakravartty A. (2004), "Structuralism as a Form of Scientific Realism," International Studies in the Philosophy of Science 18(2-3), 151-171. https://doi.org/10.1080/02698 59042000296503

Chakravartty A. (2007), A Metaphysics for Scientific Realism: Knowing the Unobservable, Cambridge: Cambridge University Press. https://doi.org/10.1017/CBO9780511487354

Chakravartty A. (2012), "Ontological Priority: The Conceptual Basis of Non-eliminative, Ontic Structural Realism” [in:] Structural Realism: Structure, Object, and Causality, 
E. M. Landry, D. P. Rickles (eds.), New York: Springer, 187-206. https://doi.org/ 10.1007/978-94-007-2579-9_10

Chakravartty A. (2017a), "Case Studies, Selective Realism, and Historical Evidence" [in:] EPSA15 Selected Papers. The 5th Conference of the European Philosophy of Science Association in Düsseldorf, M. Massimi, J. W. Romeijn, G. Schurz (eds.), Heidelberg: Springer, 13-23. https://doi.org/10.1007/978-3-319-53730-6_2

Chakravartty A. (2017b), "Saving the Scientific Phenomena: What Powers Can and Cannot Do" [in:] Putting Powers to Work, J. J. Jacobs (ed.), Oxford: Oxford University Press, 24-37. https://doi.org/10.1093/oso/9780198796572.003.0003

Contessa G. (2007), "Representation, Interpretation, and Surrogative Reasoning," Philosophy of Science 74(1), 48-68. https://doi.org/10.1086/519478

De Vroey M. (2016), A History of Macroeconomics from Keynes to Lucas and Beyond, Cambridge: Cambridge University Press. https://doi.org/10.1017/CBO9780511843617

Debreu G. (1974), "Excess Demand Functions," Journal of Mathematical Economics 1(1), 15-21. https://doi.org/10.1016/0304-4068(74)90032-9

Ellis B. (1991), "Scientific Essentialism" (paper presented at the 1991 Conference of the Australasian Association for the History and Philosophy of Science).

Ellis B. (2008), "Powers and Dispositions" [in:] Revitalizing Causality: Realism about Causality in Philosophy and Social Science, R. Groff (ed.), London: Routledge, 76-92. https://doi.org/10.4324/9780203932636

Elsamahi M. (1994), “Could Theoretical Entities Save Realism?," Proceedings of the Biennial Meeting of the Philosophy of Science Association 1994(1), 173-180. https://doi.org/10.2307/193022

Epstein B. (2009), "Ontological Individualism Reconsidered," Synthese 166(1), 187-213. https://doi.org/10.1007/s11229-007-9272-8

Epstein B. (2014), "Why Macroeconomics Does Not Supervene on Microeconomics," Journal of Economic Methodology 21(1), 3-18. https://doi.org/10.1080/1350178X.2014.886467

Esfeld M. (2009), "The Modal Nature of Structures in Ontic Structural Realism," International Studies in the Philosophy of Science 23(2), 179-194. https://doi.org/10.1080/ 02698590903006917

Esfeld M. (2013), "Ontic Structural Realism and the Interpretation of Quantum Mechanics," European Journal for Philosophy of Science 3(1), 19-32. https://doi.org/10.1007/ S13194-012-0054-x

French S. (1998), "On the Withering Away of Physical Objects" [in:] Interpreting Bodies: Classical and Quantum Objects in Modern Physics, E. Castellani (ed.), Princeton: Princeton University Press, 93-113. https://doi.org/10.1515/9780691222042-009

French S. (2010), "The Interdependence of Structure, Objects and Dependence," Synthese 175(S1), 89-109. https://doi.org/10.1007/s11229-010-9734-2

French S., Ladyman J. (2011), "In Defence of Ontic Structural Realism" [in:] Scientific Structuralism, A. Bokulich, P. Bokulich (eds.), New York: Springer, 25-42. https:// doi.org/10.1007/978-90-481-9597-8_2

Friedman M. (1968), "The Role of Monetary Policy," The American Economic Review $58(1), 1-17$.

Friedman M., Schwartz A. J. (1963), A Monetary History of the United States, 1867-196o, Princeton: Princeton University Press.

Galbács P. (2015), The Theory of New Classical Macroeconomics: A Positive Critique, New York: Springer. https://doi.org/10.1007/978-3-319-17578-2 
Galbács P. (2020), The Friedman-Lucas Transition in Macroeconomics: A Structuralist Approach, Cambridge, MA: Elsevier Science. https://doi.org/10.1016/C2018-0-00273-X

Garfinkel A. (1981), Forms of Explanation: Rethinking the Questions in Social Theory, New Haven: Yale University Press.

Hacking I. (1982), "Experimentation and Scientific Realism," Philosophical Topics 13(1), 71-87. https://doi.org/10.5840/philtopics19821314

Hardin C. L., Rosenberg A. (1982), "In Defense of Convergent Realism," Philosophy of Science 49(4), 604-615. https://doi.org/10.1086/289080

Hardt Ł. (2018), "Economic Models and Ceteris Normalibus Laws," Economic Studies 2018(1-2), 41-70.

Hoover K. D. (2001), "Is Macroeconomics for Real?" [in:] The Economic World View: Studies in the Ontology of Economics, U. Mäki (ed.), Cambridge: Cambridge University Press, 225-245. https://doi.org/10.1017/CBO9780511752049.013

Hoover K. D. (2008), “Does Macroeconomics Need Microfoundations?” [in:] The Philosophy of Economics: An Anthology, D. M. Hausman (ed.), Cambridge: Cambridge University Press, 315-333. https://doi.org/10.1017/CBO9780511819025.022

Hoover K. D. (2009), "Microfoundations and the Ontology of Macroeconomics" [in:] The Oxford Handbook of Philosophy of Economics, H. Kincaid, D. Ross (eds.), Oxford: Oxford University Press, 386-409. https://doi.org/10.1093/oxfordhb/9780195189254. 003.0014

Hoover K. D. (2012), "Microfoundational Programs" [in:] Microfoundations Reconsidered: The Relationship of Micro and Macroeconomics in Historical Perspective, P. G. Duarte, G. T. Lima (eds.), Cheltenham: Edward Elgar, 19-61. https://doi.org/10.4337/ 9781781004104.00008

Kincaid H. (2008), "Structural Realism and the Social Sciences," Philosophy of Science 75(5), 720-731. https://doi.org/10.1086/594517

Kirman A. P. (1992), "Whom or What Does the Representative Individual Represent?," Journal of Economic Perspectives 6(2), 117-136. https://doi.org/10.1257/jep.6.2.117

Ladyman J. (1998), "What is Structural Realism?," Studies in History and Philosophy of Science Part A 29(3), 409-424. https://doi.org/10.1016/soo39-3681(98)80129-5

Lucas R. E. (1964), Substitution between Labor and Capital in U.S. Manufacturing, 19291958. Unpublished Ph.D. Dissertation, Chicago: The University of Chicago.

Lucas R. E. (1965/1981), "Distributed Lags and Optimal Investment Policy” [in:] Rational Expectations and Econometric Practice, R. E. Lucas, T. J. Sargent (eds.), Minneapolis: University of Minnesota Press, 39-54.

Lucas R. E. (1967a), “Optimal Investment Policy and the Flexible Accelerator," International Economic Review 8(1), 78-85. https://doi.org/10.2307/2525383

Lucas R. E. (1967b), "Adjustment Costs and the Theory of Supply," Journal of Political Economy 75(4), 321-334. https://doi.org/10.1086/259289

Lucas R. E. (1969), "Capital-Labor Substitution in U.S. Manufacturing” [in:] The Taxation of Income from Capital, A. C. Harberger, M. J. Bailey (eds.), Washington, DC: The Brookings Institution, 223-274.

Lucas R. E. (1972), “Expectations and the Neutrality of Money," Journal of Economic Theory 4(2), 103-124. https://doi.org/10.1016/0022-0531(72)90142-1

Lucas R. E. (1973/1976), "Econometric Policy Evaluation: A Critique," Carnegie-Rochester Conference Series on Public Policy 1976(1), 19-46. https://doi.org/10.1016/So1672231(76)80003-6 
Lucas R. E. (1977), "Understanding Business Cycles," Carnegie-Rochester Conference Series on Public Policy 1977(5), 7-29. https://doi.org/10.1016/0167-2231(77)90002-1

Lucas R. E. (1980), "Methods and Problems in Business Cycle Theory," Journal of Money, Credit and Banking 12(4), 696-715. https://doi.org/10.2307/1992030

Lucas R. E. (1981), Studies in Business-Cycle Theory, Oxford: Basil Blackwell.

Lucas R. E. (1986), “Adaptive Behavior and Economic Theory,” Journal of Business 59(4), S401-S426. https://doi.org/10.1086/296377

Lucas R. E. (1994), "Review of Milton Friedman and Anna J. Schwartz's 'A Monetary History of the United States, 1867-1960', Journal of Monetary Economics 34(1), 5-16. https://doi.org/10.1016/0304-3932(94)90055-8

Lucas R. E. (2004), "My Keynesian Education," History of Political Economy 36(5), 12-24. https://doi.org/10.1215/00182702-36-Suppl_1-12

Lucas R. E. (1960-2004 and undated), Unpublished papers. Archival material stored at the David M. Rubenstein Library, Duke University.

Lucas R. E., Rapping L. A. (1969a), "Price Expectations and the Phillips Curve," The American Economic Review 59(3), 342-350.

Lucas R. E., Rapping L. A. (1969b), "Real Wages, Employment, and Inflation," Journal of Political Economy 77(5), 721-754. https://doi.org/10.1086/259559

Lucas R. E., Rapping L. A. (1972), "Unemployment in the Great Depression: Is There a Full Explanation?,” Journal of Political Economy 8o(1), 186-191. https://doi.org/10.1086/ 259872

Lucas R. E., Sargent T. J. (1979), “After Keynesian Macroeconomics,” Federal Reserve Bank of Minneapolis Quarterly Review 3(2), 1-16. https://doi.org/10.21034/qr.321

Mäki U. (1992), "On the Method of Isolation in Economics" [in:] Intelligibility and Science, C. Dilworth (ed.), Amsterdam: Rodopi, 317-351.

Manicas P. T. (2006), A Realist Philosophy of Social Science: Explanation and Understanding, Cambridge: Cambridge University Press. https://doi.org/10.1017/CBO9780511607035

Mantel R. R. (1973), "On the Characterization of Aggregate Excess Demand," Journal of Economic Theory 7(3), 348-353. https://doi.org/10.1016/0022-0531(74)90100-8

Morganti M. (2004), "On the Preferability of Epistemic Structural Realism," Synthese 142(1), 81-107. https://doi.org/10.1023/B:SYNT.0o00047712.39407.c3

Morrison M. (1990), “Theory, Intervention and Realism," Synthese 82(1), 1-22. https:// doi.org/10.1007/BFo0413667

Phelps E. S. (ed.) (1970), The Microeconomic Foundations of Employment and Inflation Theory, New York: W. W. Norton

Psillos S. (1995), “Is Structural Realism the Best of Both Worlds?," Dialectica 49(1), 15-46. https://doi.org/10.1111/j.1746-8361.1995.tboo113.x

Psillos S. (2001), "Is Structural Realism Possible?," Philosophy of Science 68(3), S13-S24. https://doi.org/10.1086/392894

Resnik D. B. (1994), "Hacking's Experimental Realism," Canadian Journal of Philosophy 24(3), 395-412. https://doi.org/10.1080/00455091.1994.10717376

Ross D. (2008), “Ontic Structural Realism and Economics," Philosophy of Science 75(5), 732-743. https://doi.org/10.1086/594518

Sargent T. J. (1977), Is Keynesian Economics a Dead End? Working Paper, No. 101, Minnesota: University of Minnesota. https://doi.org/10.21034/wp.101

Simon H. A. (1969/1996), The Sciences of the Artificial, Cambridge, MA: The MIT Press. 
Sonnenschein H. (1972), "Market Excess Demand Functions," Econometrica 40(3), 549563. https://doi.org/10.2307/1913184

Sonnenschein H. (1973), "Do Walras' Identity and Continuity Characterize the Class of Community Excess Demand Functions?,” Journal of Economic Theory 6(4), 345-354. https://doi.org/10.1016/0022-0531(73)90066-5

Stanford P. K. (2003), "Pyrrhic Victories for Scientific Realism," The Journal of Philosophy 100(11), 553-572.

Stigler G. J. (1961), “The Economics of Information," Journal of Political Economy 69(3), 213-225. https://doi.org/10.1086/258464

Stigler G. J. (1962), "Information in the Labor Market," Journal of Political Economy 70(5), 94-105. https://doi.org/10.1086/258727

Suárez M. (2002), The Pragmatics of Scientific Representation. Centre for Philosophy of Natural and Social Science (CPNSS) Discussion Paper Series, DP 66/o2, London: CPNSS/London School of Economics.

Suárez M. (2004), “An Inferential Conception of Scientific Representation," Philosophy of Science 71(5), 767-779. https://doi.org/10.1086/421415

Swoyer C. (1991), "Structural Representation and Surrogative Reasoning," Synthese 87(3), 449-508. https://doi.org/10.1007/BFoo499820

Tobin J. (1952), “Money Wage Rates and Employment” [in:] The New Economics: Keynes' Influence on Theory and Public Policy, S. E. Harris (ed.), New York: Knopf, 572-590.

van Fraassen B. (2007), "Structuralism(s) about Science: Some Common Problems," Aristotelian Society Supplementary Volume 81(1), 45-61. https://doi.org/10.1111/j.14678349.2007.00150.x

Worrall J. (1989), "Structural Realism: The Best of Both Worlds," Dialectica 43(1-2), 99124. https://doi.org/10.1111/j.1746-8361.1989.tboo933.x 